\title{
Geminin regulates neuronal differentiation by antagonizing Brg1 activity
}

\author{
Seongjin Seo, ${ }^{1}$ Anabel Herr, ${ }^{2}$ Jong-Won Lim, ${ }^{1}$ Genova A. Richardson, ${ }^{1}$ Helena Richardson, ${ }^{2}$ \\ and Kristen L. Kroll ${ }^{1,3}$ \\ ${ }^{1}$ Department of Molecular Biology and Pharmacology, Washington University School of Medicine, St. Louis, Missouri \\ 63110, USA; ${ }^{2}$ Peter MacCallum Cancer Centre, East Melbourne, Victoria, 3002, Australia
}

Precise control of cell proliferation and differentiation is critical for organogenesis. Geminin (Gem) has been proposed to link cell cycle exit and differentiation as a prodifferentiation factor and plays a role in neural cell fate acquisition. Here, we identified the SWI/SNF chromatin-remodeling protein Brg1 as an interacting partner of Gem. Brg1 has been implicated in cell cycle withdrawal and cellular differentiation. Surprisingly, we discovered that Gem antagonizes Brg1 activity during neurogenesis to maintain the undifferentiated cell state. Down-regulation of Gem expression normally precedes neuronal differentiation, and gain- and loss-of-function experiments in Xenopus embryos and mouse P19 cells demonstrated that Gem was essential to prevent premature neurogenesis. Misexpression of Gem also suppressed ectopic neurogenesis driven by Ngn and NeuroD. Gem's activity to block differentiation depended upon its ability to bind Brg1 and could be mediated by Gem's inhibition of proneural basic helix-loop-helix (bHLH)-Brg1 interactions required for bHLH target gene activation. Our data demonstrate a novel mechanism of Gem activity, through regulation of SWI/SNF chromatin-remodeling proteins, and indicate that Gem is an essential regulator of neurogenesis that can control the timing of neural progenitor differentiation and maintain the undifferentiated cell state.

[Keywords: Brg1; Geminin; neurogenesis; proneural bHLH; SWI/SNF chromatin-remodeling complex; Xenopus] Supplemental material is available at http://www.genesdev.org.

Received March 29, 2005; revised version accepted May 26, 2005.

Formation of the nervous system during vertebrate embryonic development is a complex process requiring precise coordination between cellular programs that control the determination of proliferating neuronal progenitors and those that govern cell cycle exit and terminal differentiation to generate functional neurons. Precise temporal control of the transition from proliferation to differentiation is particularly critical, as either precocious or delayed onset of differentiation results in abnormal development of the nervous system (Cremisi et al. 2003; Ohnuma and Harris 2003).

In recent years a number of molecules that regulate various aspects of neurogenesis have been identified. The initial formation of proliferating neural precursors is marked by the expression of members of the SoxB1 subfamily of HMG box transcription factors, and these proteins have been recently shown to be essential for maintaining the proliferating precursor state (Bylund et al. 2003; Graham et al. 2003). Later commitment of speci-

${ }^{3}$ Corresponding author.

E-MAIL kkroll@molecool.wustl.edu; FAX (314) 362-7058.

Article and publication are at http://www.genesdev.org/cgi/doi/10.1101/ gad.1319105. fied progenitors to a neuronal fate is governed by the expression of transcription factors in the basic helixloop-helix (bHLH) family, including the Neurogenin proteins, which are related to Drosophila Atonal (Bertrand et al. 2002). In addition to activating transcription of downstream genes involved in acquisition of neuronal fate, these bHLH factors activate a subprogram of gene expression required for exit from the cell cycle prior to terminal differentiation (Farah et al. 2000; Bertrand et al. 2002). This transition is likely to entail both chromatin reorganization and extensive changes in gene expression.

Nonamniotic vertebrates such as Xenopus laevis undergo primary neurogenesis during early embryonic development to generate a simple nervous system allowing tadpole locomotion. In Xenopus, the presumptive neural plate is marked at early gastrulation by the expression of several nuclear factors, including Sox2, Sox3, and Geminin (Gem) (Penzel et al. 1997; Kroll et al. 1998; Mizuseki et al. 1998). Subsequently, the Xenopus bHLH protein Neurogenin-related-1 (X-Ngnr-1) is expressed in a subset of these cells to generate three stripes of primary neurons at medial, intermediate and lateral positions (Ma et al. 1996). These cells later give rise respectively to future motor-, inter-, and sensory neurons. X-Ngnr-1 activates 
expression of downstream genes, including $\mathrm{p} 27^{\mathrm{Xic} 1}$, a cyclin-dependent kinase inhibitor involved in regulating cell cycle exit (Vernon et al. 2003) and the bHLH protein X-NeuroD (Lee et al. 1995; Vernon et al. 2003). X-Ngnr-1 also activates expression of the Notch pathway ligand X-Delta-1, which laterally inhibits surrounding cells from developing as neurons, and the zinc-finger transcription factor MyT1, which renders the primary neurons resistant to lateral inhibition. Finally, X-NeuroD acts in post-mitotic neurons to promote a differentiation program, which includes activation of markers of terminal differentiation (Bertrand et al. 2002). In the mammalian central and peripheral nervous system, three X-Ngnr-1-related genes (Ngn1-3) are present in proliferating neuronal precursors, while mammalian genes related to X-NeuroD include the mouse ortholog, NeuroD/ BETA2, and three other closely related proteins, NeuroD2/NDRF, NeuroM/MATH3, and MATH2/NEX2 (for review, see Chae et al. 2004).

Gem represents another potential regulator of transcriptional events during early neural development. Gem was identified based on its ability to expand the neural plate at the expense of nonneural ectoderm when overexpressed (Kroll et al. 1998). Gem has also been characterized as molecule with a role in regulating normal chromosomal ploidy and cell cycle progression (McGarry and Kirschner 1998; Mihaylov et al. 2002; Melixetian et al. 2004; Zhu et al. 2004): Gem associates with Cdt1, a component of the prereplication complex, and blocks the recruitment of Mcm complex to replication origins (McGarry and Kirschner 1998; Wohlschlegel et al. 2000; Tada et al. 2001). Therefore, Gem prevents reinitiation of DNA replication within the cell cycle to maintain chromosomal integrity and prevent aneuploidy. More recently, Gem has been shown to affect the activity of Hox and Six transcription factors in the mouse embryo and medaka retina, respectively, and was proposed to link cell cycle exit and differentiation (Del Bene et al. 2004; Luo and Kessel 2004; Luo et al. 2004).

While Gem can regulate cell fate and differentiation in several contexts, the molecular basis of its activities in these processes was unclear. To address this issue, we undertook a two-hybrid screen for Gem-interacting proteins and isolated Brg1, the catalytic subunit of the SWI/ SNF chromatin-remodeling complex, as a major known hit. The SWI/SNF complex is a multisubunit complex (seven to 13 proteins) with a total molecular mass of $\sim 2$ MDa that uses ATP to locally disrupt histone-DNA associations and relocate nucleosomes to alternate positions (Kingston and Narlikar 1999; Whitehouse et al. 1999). SWI/SNF complexes have previously been shown to associate with various sequence-specific transcription factors and with histone acetyltransferases (HATs) and histone deacetylases (HDACs) to activate or repress target genes (Peterson and Logie 2000; Kadam and Emerson 2003). In mammals, SWI/SNF complexes are composed of either one of two catalytic subunits, Brahma (Brm) or Brahma-related gene 1 (Brg1) (Martens and Winston 2003), and play a critical role in transcriptional regulation in a number of processes including cell proliferation and differentiation (Gebuhr et al. 2000; Martens and Winston 2003).

Recently, we determined that Brg1 activity played a critical role in primary neurogenesis in Xenopus and neuronal differentiation in mammalian P19 embryonic carcinoma cells (Seo et al. 2005). Inhibition of Brg1 activity resulted in an expansion of the proliferating neuronal precursor population and inhibition of neuronal differentiation. We demonstrated that Brgl interacted with the Xenopus Neurogenin (X-Ngnr-1) and X-NeuroD proteins, and found that the ability of these bHLH proneural proteins to drive neurogenesis and to transactivate their target genes required Brgl activity. Together, these data indicated that Brg1 plays a critical role in target gene activation by the bHLH factors during neurogenesis.

Here, we demonstrated that Gem regulates neurogenesis by modulating the activity of the SWI/SNF chromatin-remodeling complex. We demonstrated that Gem interacts with Brgl through a Gem C-terminal motif and found that Gem and the SWI/SNF complex act antagonistically in the Drosophila eye and wing. Gem is highly expressed in undifferentiated cells and is down-regulated before neuronal differentiation. Overexpression of Gem suppressed neurogenesis and blocked the ability of the bHLH factors Ngn and NeuroD to induce target gene expression in both Xenopus embryos and P19 cells. These activities were dependent on Gem's ability to interact with Brg1, and the Gem C terminus, which binds Brg1, was also sufficient to carry out these activities. Conversely, reducing Gem activity resulted in precocious neurogenesis. Finally we found that Gem could both block the ability of Ngn to transactivate target gene expression and could block interactions between Brg1 and the bHLH factors, with these activities again contingent on Gem's ability to bind Brg1. Together, these data indicate that Gem not only regulates the fidelity of DNA replication but is also a transcriptional regulator modulating SWI/SNF chromatin-remodeling complex activity. We suggest that during neurogenesis Gem acts as a differentiation timer controlling the transition from undifferentiated neural progenitors to differentiated neurons by modulating SWI/SNF and proneural bHLH interactions.

\section{Results}

Geminin interacts with the SWI/SNF chromatin-remodeling protein Brg1

Brg1 was identified as a major hit in a two-hybrid screen using Gem as a bait (data not shown). To validate that Gem-Brg1 interaction occurred under physiological conditions, we conducted coimmunoprecipitation (co-IP) assays using lysates from HEK293 and HeLa cells, which express both Brgl and Gem endogenously (Fig. 1A; data not shown). Anti-Brg1 antibody immunoprecipitated a protein of $\sim 30 \mathrm{kDa}$ that was recognized by several antiGem antibodies (Fig. 1A, lane 2; data not shown). Gem was not precipitated by Protein A (Fig. 1A, lane 1) or 
A

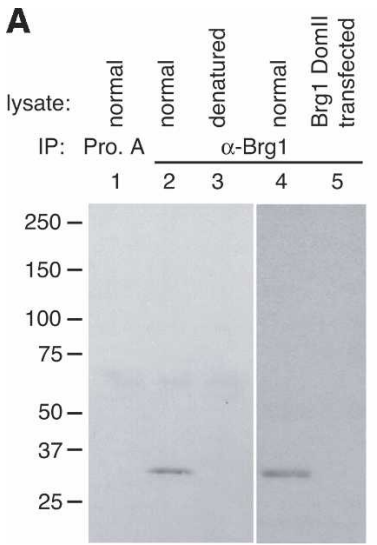

B

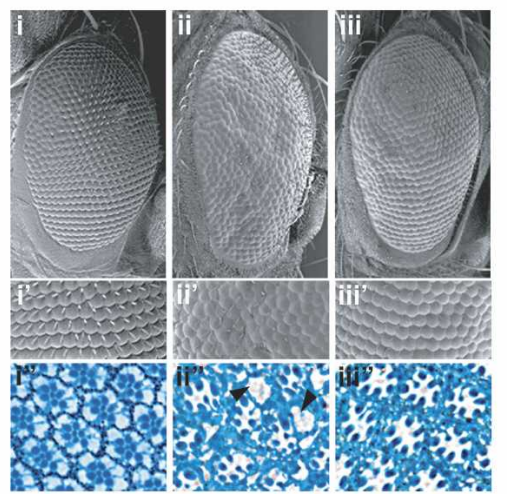

C

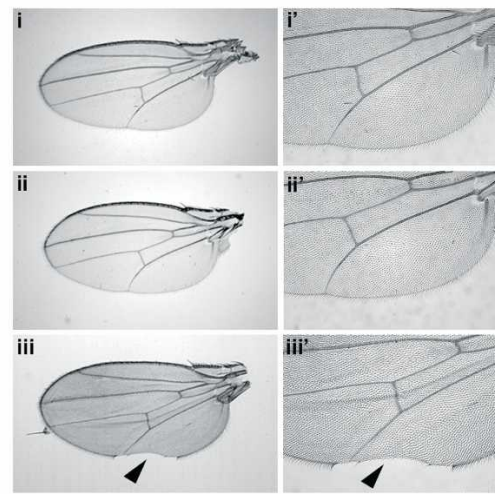

Figure 1. Gem interacts with Brg1. (A) Co-IP of Brg1 and Gem from HEK293 cell extract. (B) Scanning electron micrograph of adult male eyes from wild-type (panel i), GMR-GAL4/+; UAS-Brm ${ }^{K 804 R /+}\left(\right.$ panel ii), and GMR-GAL4/Gem ${ }^{1(2) k 03202}$; UAS-Brm ${ }^{K 804 R} /+($ panel iii). (Panels i'-iii') Higher magnification of the ventral half of the eye. (Panels i"-iii") Transverse eye sections stained for rhabdomeres. Arrowheads mark losses of photoreceptor cells. $(C)$ Overexpression of both Brm ${ }^{K 804 R}$ and wild-type Gem in the wing produces

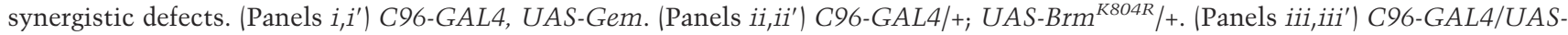
Gem; UAS-Brm ${ }^{K 804 R} /+$. Panels $i^{\prime}, i i^{\prime}$, and iii $^{\prime}$ are a higher magnification of panels $i, i i$, and iii, respectively. Note the loss of cells and bristles in panels iii and iii' (arrowheads).

when lysate was heat-denatured (Fig. 1A, lane 3). We further tested whether overexpression of Brg1 Domain II (Dom II), which is sufficient to bind Gem (see below) but not recognized by the anti-Brgl antibody used above (see Materials and Methods), could competitively block the interaction of endogenous Brgl and Gem. Indeed, endogenous Gem failed to be precipitated when Brg1 Dom II was overexpressed (Fig. 1A, lane 5), demonstrating the specificity of the Gem-Brg1 interaction.

We also analyzed the orthologous interaction genetically in Drosophila. Drosophila Brm is the single ortho$\log$ of mammalian Brg1 and Brm. Overexpression of dominant-negative $\mathrm{Brm}\left(\mathrm{Brm}^{\mathrm{K} 804 R}\right)$ using the GMR-Gal4 driver, which is expressed in the posterior region of the third instar larval eye disc, led to a rough eye phenotype (Brumby et al. 2002) with severe disruption of the ommatidial pattern and loss of photoreceptor cells (Fig. 1B). On this background, halving the dosage of Gem using $\mathrm{Gem}^{1(2) \mathrm{k} 03202}$ mutant, which has been shown to reduce Gem protein levels significantly (Quinn et al. 2001), greatly reduced the severity of the Brm ${ }^{K 804 R}$ rough eye phenotype (Fig. 1B). In addition, simultaneous overexpression of wild-type Gem and $\mathrm{Brm}^{K 804 R}$ in the adult wing resulted in synergistic defects, including loss of tissue and bristles in the posterior region of the wing margin (Fig. 1C). Together these data indicate that Gem and Brm genetically interact and act in an antagonistic manner in the Drosophila eye and wing.

\section{Geminin interacts with Brg1 and Brm Domain II through its C-terminal motif}

To define interacting regions within Gem and Brgl, we generated a series of deletion mutants for both Brgl and Gem (Fig. 2A,C) and assayed these proteins for interaction. In co-IP experiments, Brg1 Dom II (amino acids
342-598) strongly associated with Gem, while other regions of Brg1 (Dom I and Dom III + IV) did not (Fig. 2B). Analysis of Gem variants revealed that Gem amino acids 160-175 was necessary for interaction with Brg1 Dom II and that the C-terminal domain (Gem CT; amino acids 142-206) was sufficient for this interaction (Fig. 2D). To our knowledge, no interacting proteins or activities have been previously assigned to the Gem CT to date. This result also suggested that Gem homo-dimerization, which is mediated by the coiled-coil domain (amino acids 107-141) (Saxena et al. 2004; our unpublished data), was not required for Brg1-Gem interaction.

To determine whether Gem and Brgl interact directly or indirectly, we conducted a GST pull-down assay using purified GST-Gem fusion protein and in vitro translated Brgl. In this assay, while GST alone did not coprecipitate with Brg1, GST-Gem fusion protein specifically coprecipitated Brg1 (Fig. 1E), showing that Gem and Brgl interact directly.

As Brg1 Dom II and Gem CT contain many basic amino acids $(p I=10.07)$ and acidic amino acids $(p I=3.51)$, respectively, and the Gem-Brg1 complex was disrupted under high-salt conditions (Supplementary Fig. 1A), it is possible that Gem-Brgl association is dependent on electrostatic interactions between positively and negatively charged amino acids in the two proteins. Thus, we tested whether acidic amino acids in the Gem CT are critical for the Gem-Brg1 interaction. Glutamic (E) and aspartic (D) acids in this region were substituted to glutamine (Q) and asparagine (N), respectively (Fig. 2F). CoIP assays revealed that five acidic amino acids between amino acids 170 and 176 were critical for Gem-Brg1 interaction (Fig. 2G). Substitution of those amino acids together completely abolished the Gem-Brg1 interaction (5EQ) (Fig. 2G). Deletion of Gem amino acids 161-176 $[\Delta(\mathrm{Brg} 1-$ binding domain, $\mathrm{BD})]$ also abolished interac- 
Seo et al.
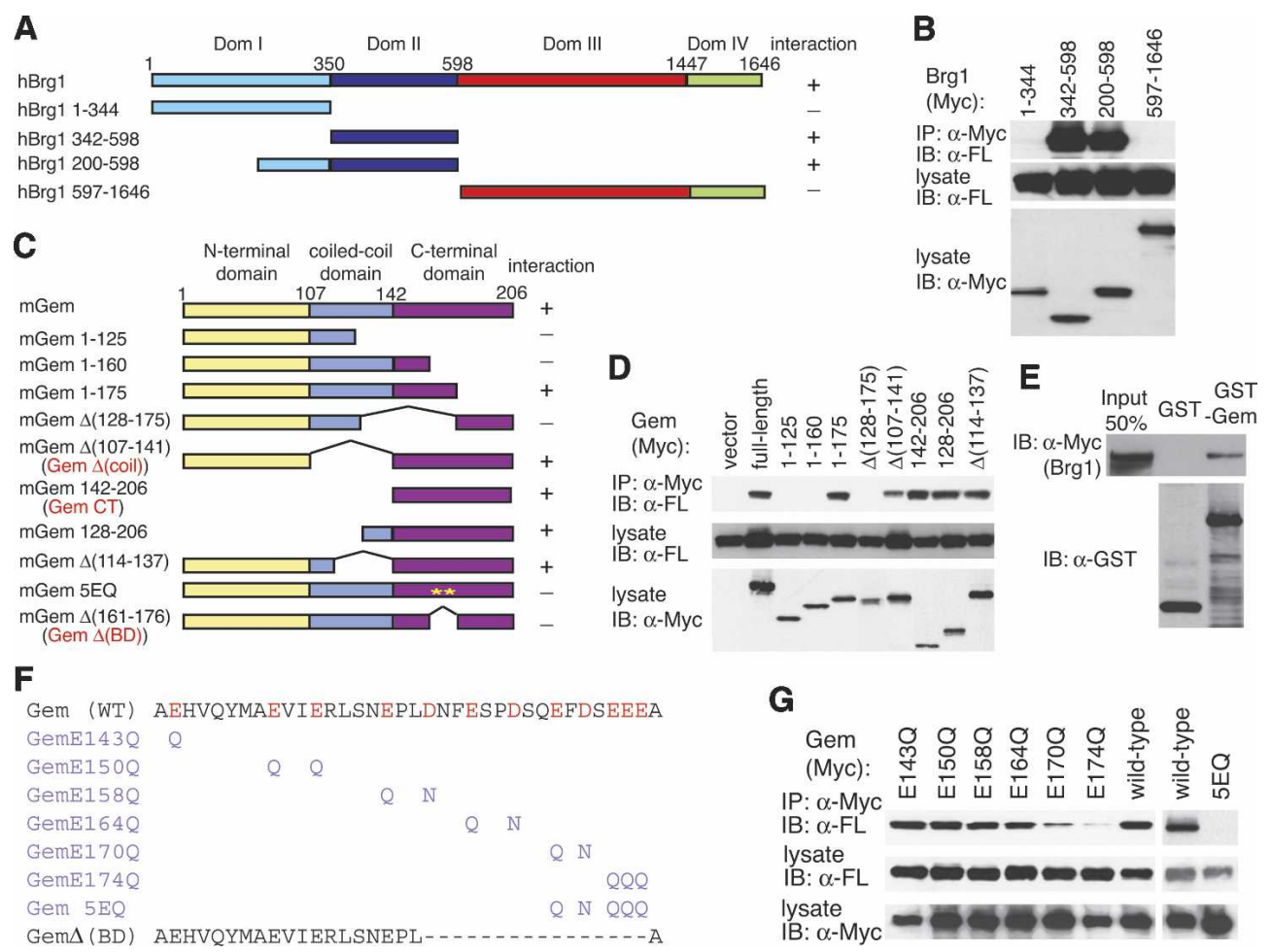

Figure 2. Geminin interacts with Domain II of Brg1 through its C terminus. (A) Schematics for Brgl deletion constructs used to map Gem-interacting domain and summary of the result. Numbers denote amino acid positions. (B) Co-IP assays with Myc-tagged Brg1 deletion mutants and Flag-Gem. $(C)$ Schematics for Gem deletion constructs used to map Brgl-interacting domain and summary of the result. Numbers denote amino acid positions. Asterisks depict the substitution of five acidic amino acids to neutral ones with similar side-chains in the Gem C terminus. (D) Co-IP assays with Myc-Gem deletion mutants and Flag-Brg1 Dom II. (E) GST-pull down assay reveals that Gem directly interacts with Brg1. GST and GST-Gem proteins were purified from E. coli, and Myc-Brg1 was generated by in vitro translation. After GST pull-down, bound proteins were analyzed by anti-Myc Western blotting, revealing specific and direct interaction of Gem and Brg1. (F) Amino acid sequences (amino acids 142-177) of wild-type and mutant Gem variants used in G. Acidic amino acids were color-coded in red. In mutant Gem variants, glutamic acid (E) and aspartic acid (D) were replaced with glutamine (Q) and aspargine $(\mathrm{N})$, respectively. Other amino acids were identical and are not shown. Deleted amino acids in Gem $\Delta(\mathrm{BD})$ were depicted as a dash $(-) . \Delta(\mathrm{BD})$ indicates deletion of Brg1-binding domain. $(G)$ Co-IP assays using mutated Gem variants.

tion (data not shown). We likewise found that Gem associated with Brm through the same domain (Supplementary Fig. 1B) and found that interaction with Brm was also abolished by the Gem 5EQ mutation (Supplementary Fig. 1C). However, as Brm has not been characterized as having a role in early vertebrate embryogenesis, we focused our study on the functional relevance of Gem-Brg1 interaction.

Geminin and Brg1 have overlapping expression profiles in the embryonic nervous system

To determine where Gem-Brg1 interactions could occur during embryonic development, we compared their expression patterns. Xenopus Brg1 was expressed ubiquitously until mid-neurula stages and gradually restricted to the CNS and neural crest-contributing organs (Fig. $3 \mathrm{~A}-\mathrm{C}$; Seo et al. 2005). Zygotic X-Gem expression was detected from the early gastrula stage (stage 10) in the prospective neural plate and maintained through gastrulation (Fig. 3D-H). At tailbud stages, the expression patterns of $X-G e m$ and $X-B r g 1$ were very similar. Thus, $B r g 1$ and Gem have temporally and spatially overlapping expression profiles in neural tissues.

We recently demonstrated that $\mathrm{Brg} 1$ is required for neuronal differentiation (Seo et al. 2005). Gem has been implicated in the acquisition of general neural fate (Kroll et al. 1998), but its role during neuronal differentiation was unknown. We thus analyzed changes in Gem expression during neurogenesis. During Xenopus primary neurogenesis, the neuroectoderm is a bilayer consisting of superficial and deep layers. Both layers express panneural markers such as NCAM and acquire a general neural fate (Chalmers et al. 2002). However, committed neural precursors expressing the proneural genes Ngnr1 and NeuroD arise exclusively in the deep layer beginning at stage 11.5-12 (Lee et al. 1995; Ma et al. 1996; Chalmers et al. 2002). Differentiated neurons, marked by $N$ tubulin, are generated beginning at stage 14 only in the deep layer (Fig. 3I; Ma et al. 1996; Chalmers et al. 2002). The superficial layer is resistant to neuronal differentiation signals and contributes to later secondary neurogenesis (Chalmers et al. 2002). Analysis of Gem expression during neurogenesis revealed an inverse correlation be- 


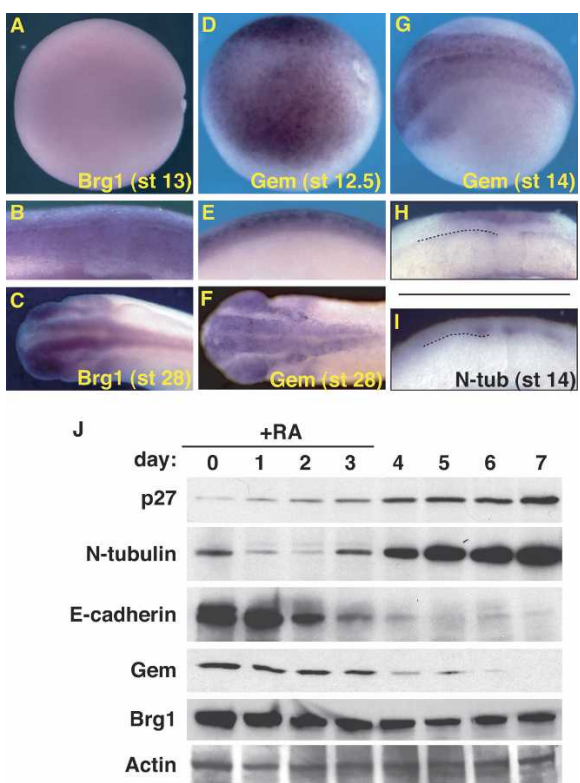

Figure 3. Brg1 and Gem have overlapping expression patterns but Gem diminishes prior to neuronal differentiation. In situ hybridization for $X$-Brg1 $(A-C)$ and $X$-Gem $(D-H)$ in Xenopus embryos. $(A, D, G)$ Dorso-lateral views. $(C, F)$ Dorsal views at tailbud stages; anterior toward left. $(B, E, H)$ Transverse sections at stages shown in $A, D$, and $G$, respectively. (I) Transverse section of $N$-tubulin-stained embryo. In $H$ and $I$, a dashed line marks the neural plate-somite boundary. (J) Expression profile of Gem and other markers during RA-induced neuronal differentiation of $\mathrm{P} 19$ cells.

tween Gem and N-tubulin expression. Until stage 12.5, Gem was detected in both layers of neuroectoderm (Fig. 3E). Subsequently, however, Gem expression diminished in the deep layer, and by stage $14 \mathrm{Gem}$ was exclusively detected in the superficial layer (Fig. $3 \mathrm{H}$ ).

The mouse P19 embryonic carcinoma cell line is a tractable system for analyzing neuronal differentiation (McBurney 1993; Bain et al. 1995). Upon retinoic acid (RA) treatment and aggregation, P19 cells differentiate into neurons and glia. Under different conditions, these cells develop as skeletal or cardiac muscle, endoderm, or other cell types. Transfection of proneural bHLH proteins such as NeuroD and MASH1 is also sufficient to induce neuronal differentiation from P19 cells in the absence of RA and aggregation (Farah et al. 2000). These differentiating neurons undergo alterations in morphology such as neurite extension, cell cycle withdrawal, expression of neuron-specific proteins, and the acquisition of electrical signaling capabilities, suggesting that this neuronal differentiation program recapitulates many aspects of in vivo neurogenesis (Farah et al. 2000).

Neuronal differentiation of P19 cells was induced by aggregation in the presence of RA, and the expression of Gem was compared with several markers of the neuronal differentiation process (Fig. 3J). As seen for Xenopus primary neurogenesis, Gem expression during RA-induced neuronal differentiation of P19 cells also demonstrated an inverse correlation with expression of $N$-tubulin and with the Cdk-inhibitor $p 27^{\text {Kip } 1}$, which promotes cell cycle withdrawal accompanying differentiation. Expression of $\mathrm{N}$-tubulin and $p 27^{\text {Kip } 1}$ increased on day 4 following RA induction. Conversely, levels of E-cadherin, which are reduced accompanying neuronal differentiation (Gao et al. 2001), decreased by day 3. The level of Gem expression showed a similar decrease during differentiation. Brg1 protein levels remained constantly during neuronal differentiation after RA induction. Thus in both Xenopus and mammalian cells, Gem and Brg1 are coexpressed at high levels in undifferentiated precursors, but Gem levels decrease during neuronal differentiation.

\section{Misexpression of Geminin inhibits neuronal differentiation}

Based on the observations that Brg1 is required for neurogenesis (Seo et al. 2005), that Gem is down-regulated before neuronal differentiation, and that Gem and Brm (the Brg1 ortholog in Drosophila) act antagonistically, we hypothesized that Gem might inhibit neuronal differentiation and tested this hypothesis by both gain- and loss-of-function approaches. As overexpression of wildtype Gem in Xenopus caused developmental arrest and cell death before gastrulation (McGarry and Kirschner 1998; data not shown), we used the coiled-coil domain deletion mutant, Gem $\Delta($ coil), which still interacts with Brg1 but not with Cdt1, the DNA replication licensing factor whose activity is inhibited by Gem (Saxena et al. 2004; our unpublished data). In parallel we analyzed the $\operatorname{Gem} \Delta$ (coil) variants, Gem $\Delta$ (coil) $5 \mathrm{EQ}$ and $\operatorname{Gem} \Delta(\operatorname{coil}) \Delta(\mathrm{BD})$, which are defective in Brg1 binding.

As expected from prior results (Kroll et al. 1998), expression of the general neural marker NCAM was expanded by misexpression of Gem $\Delta$ (coil) (Fig. 4A). Despite the expanded neural territory, embryos failed to show an increase in differentiated neurons, and $N$-tubulin expression was instead suppressed by $\operatorname{Gem} \Delta$ (coil) (Fig. 4D). This suppression of $N$-tubulin by Gem overexpression was reminiscent of the failure of neuronal differentiation following Brg1 loss of function (Fig. 4I; Seo et al. 2005). Analysis of Gem $\Delta(\operatorname{coil}) 5 E Q$ and Gem $\Delta$ (coil) $\Delta(\mathrm{BD})$ demonstrated comparable expansion of the NCAM-positive territory (Fig. 4B,C), confirming previous observations that the Gem N-terminal domain was sufficient to expand the neural territory (Kroll et al. 1998). However, in contrast with $\operatorname{Gem} \Delta$ (coil), $\operatorname{Gem} \Delta(\operatorname{coil}) 5 E Q$ and Gem $\Delta(\operatorname{coil}) \Delta(\mathrm{BD})$ overexpression increased $\mathrm{N}$-tubulin-expressing cells on the injected side (Fig. 4E,F). We suggest that this increase may result from induction of more neural tissue while neurogenesis is no longer inhibited in that area. Together, these results indicate that while Gem promotes general neural fate acquisition, it can block neuronal differentiation and that this activity of Gem depends on the presence of an intact Brg1-binding motif. While overexpression of GemCT, which was sufficient to bind Brgl, also efficiently blocked $N$-tubulin expression (Fig. 4G), a variant of Gem $\mathrm{CT}$ that was severely reduced for Brgl binding had little effect on $\mathrm{N}$-tubulin expression (Fig. $4 \mathrm{H}$ ). These differen- 
Seo et al.

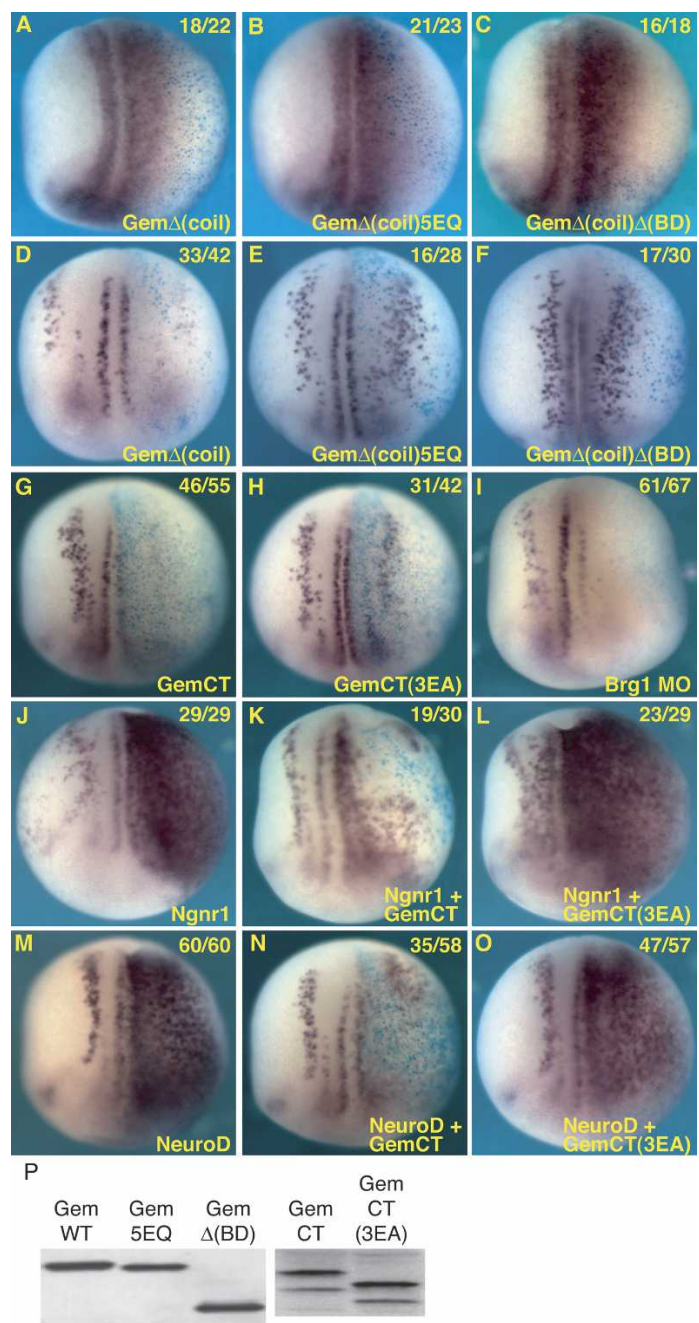

Figure 4. Misexpression of Gem prevents neurogenesis. $(A-O)$, Two-cell stage Xenopus embryos were injected in one cell as indicated (yellow) with $\beta$-galactosidase mRNA coinjection for lineage tracing and analyzed for NCAM $(A-C)$ or N-tubulin $(D-$ $O)$ expression. (CT) C-terminal region. 3EA is an alanine substitution mutant of acidic amino acids 188-190 in Xenopus Gem (which correspond to mouse Gem amino acids 174-176). Like GemE174Q (Fig. 2F,G), Xenopus Gem 3EA has severely reduced Brg1 binding (data not shown). Numbers indicate the number of affected embryos over the total number of embryos. In situ for markers is stained purple, and blue X-gal staining marks the injected side. Injected sides were oriented rightward. $(P)$ Expression levels of Gem variants injected into Xenopus embryos. Embryos were injected as indicated at the two-cell stage and harvested at stage 12 to prepare lysates. Ten embryos were used for each sample, and one embryo-equivalent of lysate was loaded per lane for Western blotting with anti-Myc antibody.

tial effects were not due to observable differences in the expression level or stability of proteins produced from different constructs (Fig. 4P). These data indicate that GemCT has the ability to suppress neurogenesis.

We previously found that the bHLH proneural proteins Ngnrl and NeuroD require Brgl activity to induce neurogenesis (Seo et al. 2005). Since overexpression of Gem mimicked effects of Brg1 loss of function, we tested whether the ability of Ngnrl and NeuroD to induce neuronal differentiation was likewise sensitive to Gem overexpression. Whereas injection of Ngnr1 or NeuroD induced extensive ectopic neurogenesis (Fig. 4J,M), we found that coinjection of wild-type, but not Brg1 binding-defective, GemCT strongly suppressed the ability of Ngnrl and NeuroD to promote ectopic neurogenesis (Fig. 4K,L,N,O). These results suggest that Gem can inhibit neurogenesis elicited by bHLH proteins and that this activity requires an intact Brg1-binding motif.

To investigate whether Gem's ability to inhibit neurogenesis is conserved in mammals, P19 cells were transiently transfected with plasmids expressing NeuroD2, E12, and GFP together with wild-type or Brg1 bindingdefective Gem variants, and were examined for neuronspecific class III $\beta$-tubulin expression (Fig. 5). Transfection of $800 \mathrm{ng}$ of CS2-NeuroD2 efficiently induced TuJ1positive neurons $(75.3 \% \pm 4.0 \%$ of transfected cells; average data from three experiments). Cotransfection of either wild-type Gem or dominant-negative Brg1 (DNBrg1) decreased the ability of NeuroD2 to induce TuJ1positive cells $(37.4 \% \pm 3.0 \%$ and $34.9 \% \pm 12.1 \%$, respectively). In contrast, $\mathrm{Gem} \Delta(\mathrm{BD})$ was unable to suppress neuronal differentiation by NeuroD2 $(73.6 \% \pm 3.3 \%)$.

\section{Reduction of Geminin activities causes premature neurogenesis}

As a complementary approach, we investigated whether loss of Gem function affected neurogenesis. For this purpose, we used anti-sense morpholino oligonucleotides for X-Gem (GemMO), which were previously shown to reduce Gem expression specifically and effectively (McGarry 2002). As previously described (McGarry 2002), high doses (>3.5 ng) of GemMO caused cell cycle arrest and subsequent embryonic lethality before neural induction (data not shown). Therefore we titrated the GemMO. Intermediate doses (2.5-3.0 ng) of GemMO

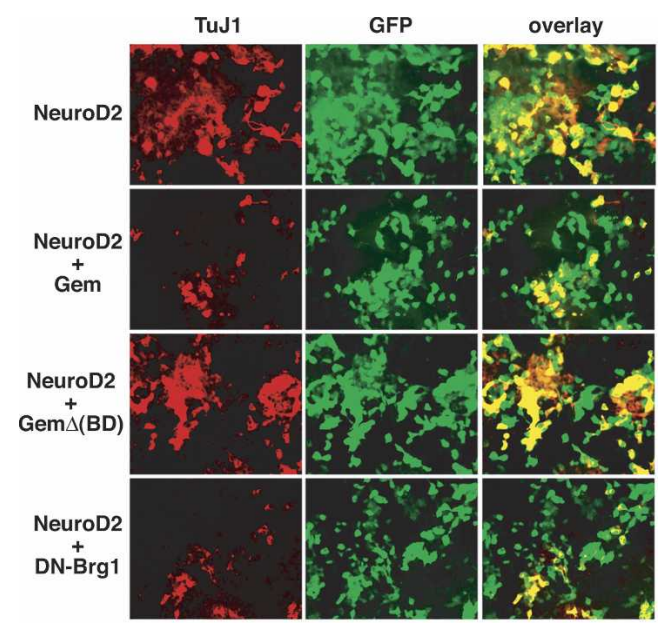

Figure 5. Gem misexpression inhibits neuronal differentiation of mouse P19 cells driven by NeuroD2. P19 cells were transfected as indicated together with GFP expression vectors to identify transfected cells and subjected to immunofluorescence with TuJ1 to detect neurons. 
suppressed Sox2 $(57 \%, n=30), \operatorname{NCAM}(85 \%, n=27)$, and $N$-tubulin $(74 \%, n=34)$ expression and caused encroachment of epidermal keratin $(36 \%, n=25)$ expression into the neural plate (Fig. 6A-D). These data suggested that Gem is required for the acquisition or maintenance of neural fate. However, loss of $N$-tubulin expression at this dose might be secondary to loss of properly formed neuroectoderm and neural progenitors, which are a prerequisite to generate differentiated neurons, rather than reflecting the requirement of Gem in neurogenesis. Therefore, we tested lower doses of GemMO (1.2-2 ng) that would have a less severe effect on initial neural fate acquisition. At these doses of GemMO, many embryos showed normal $N$-tubulin expression (data not shown). However, $\sim 10 \%$ of embryos showed premature neuronal differentiation on the injected side $(n=115)$ (Fig. 6E,F): The medial and lateral stripes of $N$-tubulin were extended, and the width of the lateral stripe was wider on the GemMO-injected side. Injection of standard $\mathrm{MO}$, a negative control, at doses up to $30 \mathrm{ng}$, did not alter NCAM or N-tubulin expression (Fig. 6G,H). These data indicate that while Gem is required for general neural fate acquisition, reduction of Gem activity can also result in premature neuronal differentiation during Xenopus primary neurogenesis.

To determine whether reduction of Gem activity also stimulated precocious or increased neuronal differentiation in mammalian cells, we used RNAi to reduce Gem levels in P19 cells. Short hairpin RNAs were transcribed from the mouse U6 promoter (Vojtek et al. 2003). $\mathrm{XASH} 3$, a Xenopus gene, was used as a negative control (Vojtek et al. 2003). Transfection of U6-Gem\#1 and U6Gem\#6 specifically reduced Gem levels (Fig. 6I). We analyzed effects of these shRNAs on neurogenesis in the presence of a low NeuroD2 level (50 ng) that was sub- threshold for efficient induction of TuJ1-positive neurons. Transfection of U6-XASH3, U6-Gem\#1, or U6Gem\#6 alone did not induce TuJ1-positive neurons (data not shown). Cotransfection of $50 \mathrm{ng}$ of CS2-NeuroD2 with either U6 empty vector (U6pro) or U6-XASH3 induced TuJ1-positive cells only at very low frequencies $(2.34 \% \pm 0.27 \%$ and $4.90 \% \pm 0.09 \%$, respectively) (Fig. $6 \mathrm{~J})$. However, cotransfection of $50 \mathrm{ng}$ of NeuroD2 with either U6-Gem\#1 or U6-Gem\#6 significantly increased the number of TuJ1-positive cells $(21.8 \% \pm 5.3 \%$ and $25.6 \% \pm 3.5 \%$, respectively) (Fig. 6J). Together, these data indicate that reduction of Gem activity potentiates the ability of NeuroD2 to induce neurogenesis and that this Gem activity is, at least to some extent, evolutionarily conserved.

Geminin blocks the association of Brg1 and proneural bHLH proteins and prevents the proneural gene target activation

Previously, we found that the Ngn and NeuroD proteins interacted directly with $\mathrm{Brg} 1$ and required $\mathrm{Brg} 1$ activity to activate target gene transcription (Seo et al. 2005). As we found that Gem interacts with Brg1, we examined whether Gem could form a higher-order complex with Brg1 and bHLH proteins or could compete with bHLH proteins for Brgl binding. In transfection and co-IP experiments, we did not detect bHLH-Gem interactions, while association of Brgl and Ngn/NeuroD was observed as before (Supplementary Fig. 2; Seo et al. 2005). Therefore, it is unlikely that Gem forms a complex together with bHLH factors and Brg1. Instead, we found that overexpression of wild-type Gem could inhibit the association of Ngn and NeuroD with Brg1. The ability of Gem to block Ngn/NeuroD and Brgl interaction was strongly

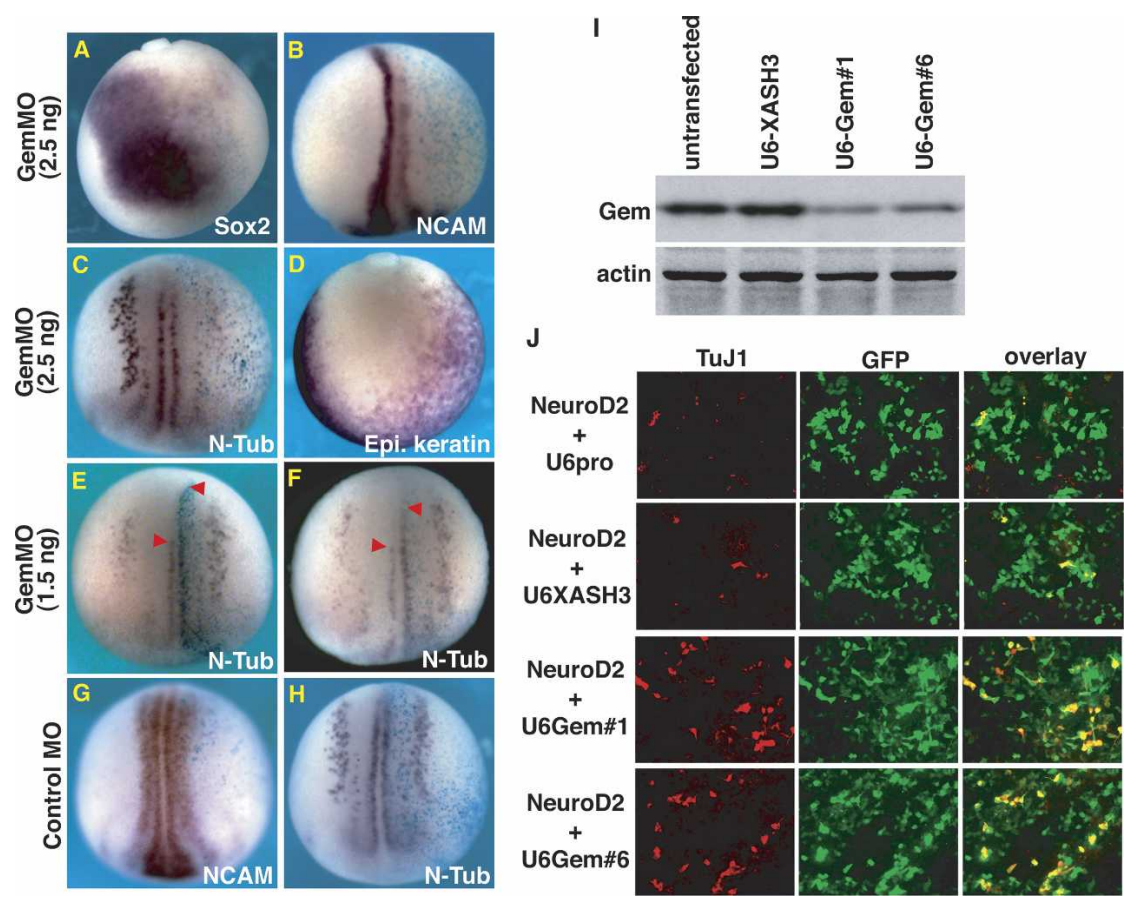

Figure 6. Loss of Gem activity results in premature neurogenesis. $(A-H)$ Xenopus embryos were injected with $2.5 \mathrm{ng}(A-D)$ or $1.5 \mathrm{ng}(E, F)$ of GemMO or $20 \mathrm{ng}$ of control MO $(G, H)$ and probed as indicated (white). Red arrowheads in $E$ and $F$ mark the posterior end of $\mathrm{N}$-tubulin expression in the medial stripe on each side of the embryo. (I) Reduction of Gem protein level in P19 cells by RNAi. (J) Reduction of Gem sensitized P19 cells to differentiate into neurons at a subthreshold level (50 ng) of NeuroD2. P19 cells were transfected as indicated and probed with TuJ1 antibody to detect neurons. GFP expression plasmid was cotransfected to trace transfected cells. 
reduced for $\mathrm{Gem} \Delta(\mathrm{BD})$, indicating that this activity requires an intact Brg1-binding motif (Fig. 7A). In addition, while wild-type Gem could suppress the ability of Ngn3 to activate target gene transcription (the multimerized E-box reporter E1X3-TATA-luc) to $50.4 \% \pm 6.6 \%$ (averaged foldchange values for three experiments), Gem $\Delta(\mathrm{BD})$ could not $(97.3 \% \pm 13.5 \%)$ (Fig. 7B). These data suggest that Gem could suppress neuronal differentiation, at least partly, by blocking association of proneural bHLHs and Brgl, and thus preventing transcriptional activation of target genes.

\section{Discussion}

Gem, Brg1, and bHLH interactions regulate the timing of neurogenesis

Molecular mechanisms that regulate the transition between cellular proliferation and differentiation are still
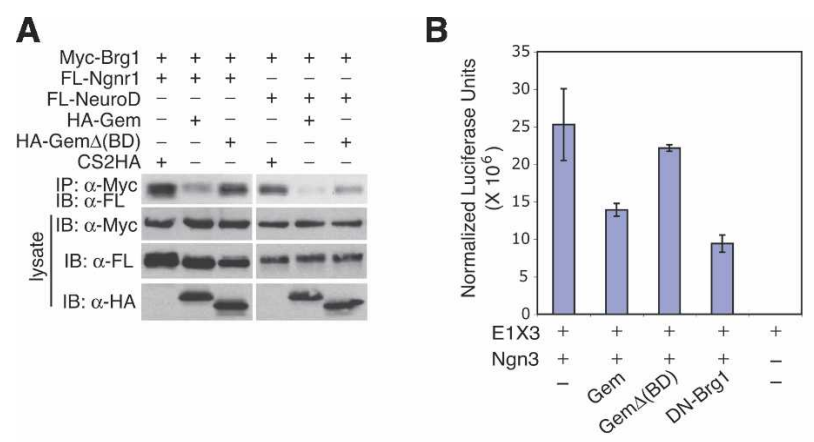

C

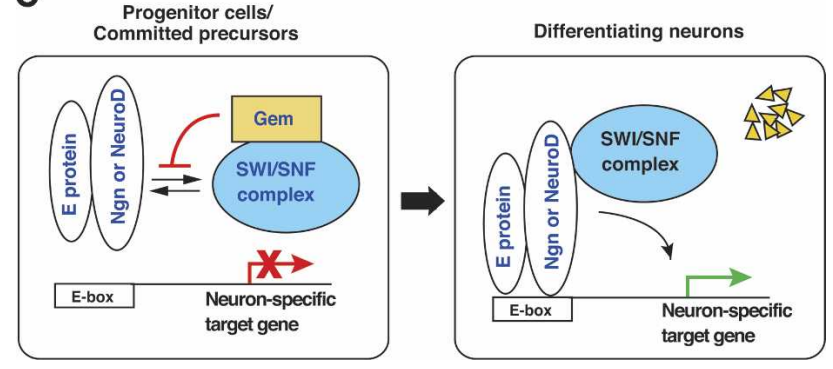

Figure 7. Gem blocks the association of Brg1 with proneural bHLH proteins and prevents transcriptional activation of their target genes. (A) Wild-type Gem can block the association of Brg1 and Ngnr1/NeuroD. HEK293 cells were transfected as indicated. Lysates were applied for co-IP assays with anti-Myc antibody. Brg1 binding-defective Gem lost the activity to block the Brg1-bHLH interaction. (B) Overexpression of Gem decreases reporter gene expression driven by Ngn3. E1X3-luciferase reporter plasmid contains triple E-boxes, which is a consensus binding site for Ngn3/bHLH class proteins. (C) Model for Gem's activity on neural progenitor cells and during neuronal differentiation. Currently, it is unknown whether proneural bHLH proteins or the SWI/SNF complex is initially recruited to E-box target sites. In progenitor cells or committed neural precursor cells, Gem is highly expressed and blocks the association of the SWI/SNF complex with proneural bHLH proteins, resulting in suppression of neuron-specific gene expression. In differentiating neurons, Gem levels diminish and SWI/SNF complexes and proneural bHLH proteins can associate to activate the transcription of neuron-specific target genes. poorly understood. Gem has been characterized as a regulator of cell fate and differentiation (Kroll et al. 1998; Del Bene et al. 2004; Luo et al. 2004), but the molecular mechanism by which Gem regulates differentiation was largely unknown. Here, we demonstrate that Gem binds to Brg1, the catalytic subunit of the SWI/SNF chromatinremodeling complex, antagonizing its ability to promote neurogenesis. Gem is highly expressed in undifferentiated neural precursor cells and negatively regulates neuronal differentiation. Gem blocks the ability of proneural bHLH proteins to promote differentiation and inhibits proneural bHLH proteins from activating their transcriptional targets. All of these Gem activities are dependent on an intact Brg1-binding site. However, in differentiating neurons, Gem levels diminish. We suggest that this Gem down-regulation normally enables differentiation to occur during neurogenesis. In keeping with this, we found that reducing Gem levels in neuronal precursors stimulated additional or precocious differentiation. Finally, we found that Gem can block Brg1-bHLH interactions previously shown to be essential to enable neuronal differentiation to occur, providing at least one mechanism by which Gem may inhibit neurogenesis through interaction with Brg1.

Together, our data are most consistent with a model whereby neuronal precursor cells, which express high levels of Gem, are blocked from differentiation through Gem's antagonism of Brgl-bHLH-dependent transcription of target genes (Fig. 7C). Reduction of Gem levels occurs prior to or during the time of cell cycle withdrawal. As Gem levels are lowered, Gem-mediated inhibition of differentiation is relieved, enabling Brgl-bHLH complexes to transactivate bHLH-dependent target genes. Thus, interactions between proneural bHLH proteins, Brg1, and Gem can critically regulate the transition from the neural progenitor to the differentiated neuronal state, with Gem activity contributing to the timing of this transition. It remains to be determined whether Gem's ability to block Brg1-bHLH interaction, which we observed in vitro, represents the major means by which Gem negatively regulates expression of bHLH targets. Alternatively, or in addition to this, Gem may recruit additional cofactors or HDACs to the regulatory region of bHLH target genes to negatively regulate their expression. Likewise, the order of recruitment of SWI/ SNF and the bHLH proteins to target genes remains to be determined.

This study also describes a novel mechanism for transcriptional regulation by Gem. Gem was recently shown to bind Hox and Six transcription factors and appeared to modulate their activities in the chick embryo and medaka retina, respectively (Del Bene et al. 2004; Luo et al. 2004). In addition, Gem was found to associate with some of the Polycomb complex members and to have a Polycomb-like activity (Luo et al. 2004). However, the mechanistic basis of Gem's ability to impact Six- and Hox-dependent transcription and to exert a Polycomblike activity remains incompletely understood. We found that Gem binds to Brgl and antagonizes its transcriptional activities. We also found that Gem can block 
the association of $\mathrm{Brg} 1$ with $\mathrm{Ngn} / \mathrm{NeuroD}$, indicating that Gem could act by regulating interactions between the SWI/SNF complex and transcription factors. Finally, the Polycomb complex is known to antagonize the SWI/ SNF complex in several contexts (Gebuhr et al. 2000; Francis et al. 2001). Therefore, the Polycomb-like activity of Gem on Hox gene expression that was previously observed could potentially be due to the direct Gem and Brgl interactions that we have observed here. Based on these data, we propose that Gem is not only an inhibitor of DNA rereplication but also a transcriptional regulator that acts by modulating the activities of SWI/SNF chromatin-remodeling enzymes.

\section{Gem maintains the undifferentiated state of neural progenitor cells}

Since Brgl is required for neuronal differentiation (Seo et al. 2005), we initially found the antagonistic relationship between Gem and Brgl that we observed surprising because it did not fit with the previous hypothesis that Gem is a prodifferentiation factor and a potential tumor suppressor (Luo and Kessel 2004). This hypothesis is largely based on Gem's ability to inhibit DNA replication. However, this hypothesis has been challenged by several observations. For example, Gem is highly expressed in proliferating cells and down-regulated in differentiated cells in a variety of different contexts (Quinn et al. 2001; Wohlschlegel et al. 2002). Misexpression of Gem stimulates the growth of some tumor cells (Ballabeni et al. 2004; Montanari et al. 2005), and increased Gem expression correlates with malignancy of tumors (Gonzalez et al. 2004; Montanari et al. 2005). In addition, Gem transcription is suppressed by $\mathrm{Rb}$ proteins and activated by E2F family members (Markey et al. 2004; Yoshida and Inoue 2004). These observations indicate that under physiological conditions high Gem activity normally correlates with and is compatible with the proliferative cell state rather than stimulating cell cycle exit.

Our data suggest that Gem is involved in the maintenance of the undifferentiated state of neural progenitor cells. Overexpression of wild-type Gem can result in cell cycle arrest in some contexts, primarily due to Gem's ability to inhibit Cdt1 function, which is necessary for initiation of DNA replication (Wohlschlegel et al. 2000; Tada et al. 2001). However, this type of cell cycle arrest following Gem overexpression is likely to involve nonphysiologically high levels of Gem. As described above, at physiological levels, the presence of Gem may not typically stimulate cell cycle exit. In fact, loss of Gem activity has also been found to result in cell cycle arrest through a different mechanism: check-point activation following partial chromosomal overreplication (McGarry 2002; Mihaylov et al. 2002; Melixetian et al. 2004). In many of our experiments, we used the coiled-coil domain deletion mutant form of Gem, which does not interact with Cdt1. Without affecting DNA replication, Gem $\Delta$ (coil) overexpression prevented neuronal differentiation, while reduction of Gem activity caused prema- ture neurogenesis. These observations suggest Gem is necessary for the maintenance of the undifferentiated state of neural precursor cells. Interestingly, the Polycomb complex protein Bmi-1 was previously found to be required for maintenance of both neural stem cells and hematopoietic stem cells (Molofsky et al. 2003; Park et al. 2003). Thus, our finding that Gem is required for the maintenance of the undifferentiated state is also consistent with the Polycomb-like activity of Gem in the avian embryo (Luo et al. 2004).

\section{Targets of bHLH, SWI/SNF complex, and Gem}

Our current understanding of molecular events that occur within committed neural precursor cells is still limited. For example, while the activities of proneural bHLH proteins in regulating neuronal cell fate determination and differentiation are well known, only a few direct transcriptional targets of these proteins have been identified. Thus the identity of direct effectors, through which Ngn and NeuroD regulate various aspects of neurogenesis, including cell cycle withdrawal and acquisition of the terminally differentiated state, remains to be determined. During the transition from neuronal precursor to differentiated neuron, extensive modulation and reorganization would be expected to occur at the chromatin level, reflecting changes in gene expression or in the "transcriptome" between the two cell states. Therefore, demonstration of a requirement for the SWI/SNF chromatin-remodeling complex for Ngn/NeuroD-driven neurogenesis and regulation of these activities by Gem represents an attractive model for analyzing transcriptional events governing neurogenesis at the chromatin level.

In many respects, molecular regulation of neurogeneisis parallels that of myogenesis. During myogenesis, the myogenic bHLH protein MyoD associates with Brg1 (Simone et al. 2004) and requires SWI/SNF-dependent chromatin remodeling for transactivation of some, but not other, groups of downstream target genes involved in regulating cell cycle exit and terminal differentiation (de la Serna et al. 2001a,b, 2005; Roy et al. 2002; Berkes et al. 2004). In addition, recruitment of SWI/SNF activity to some MyoD targets is also regulated by p38 kinase (Simone et al. 2004). During neurogenesis, it is currently unknown whether there are, likewise, differential SWI/ SNF requirements for proneural bHLH activation at particular target gene subsets. It will also be of interest to determine whether Gem affects all Brg1-bHLH-dependent target gene expression or only a subset of bHLH target genes.

In summary, we have identified a transcriptional regulatory relationship between the proneural bHLH factors, Brgl and Gem, and have determined that these interactions are essential for regulating the timing of neuronal differentiation. Gem's ability to affect bHLH-dependent transcriptional activation may be due in part to its ability to directly block Brg1-bHLH interactions, contingent on the presence of a functional Brgl-binding site. Our data reveal a new mechanism by which Gem can affect 
Seo et al.

transcription, by modulating chromatin-remodeling activity to impact bHLH-dependent transcription.

\section{Materials and methods}

Plasmids

CS2FL and CS2HA vectors were derived from CS2MT, by replacement of $6 x$ Myc with 3xFlag and HA tags, respectively (Seo et al. 2005). All Gem, Brg1, Ngn, and NeuroD constructs were subcloned into pCS2 with indicated tags at the $\mathrm{N}$ terminus. Deletion and point mutations for Gem and Brg1 were generated by PCR using primers at the indicated positions, Pfu turbo polymerase (Stratagene), and the QuickChange mutagenesis protocol (Stratagene). Primer sequences for deletion and site-directed mutagenesis are available upon request. Gem expression plasmids used for TuJ1-immunostaining and luciferase assay in P19 cells contained a D-box deletion (amino acids 23-31). U6pro and U6-XASH3 were obtained from David Turner (University of Michigan, Ann Arbor, MI). U6-Gem\#1 and U6-GEM\#6 have the following target sequences, respectively: CTGAGCATTGC TGTCTGTGA and CTGAGCATTGCTGTCTCTGA.

\section{Co-IP and Western analysis}

HEK293 and HeLa cells were grown in 10\% FBS/DMEM. To detect interaction between endogenous Brg1 and Gem, wholecell lysate from a $100-\mathrm{mm}$ dish was used for co-IP. For competition by Brg1 DomII, $10 \mu \mathrm{g}$ of pCS2 + Brg1DomII was transfected using PolyFect transfection reagent (Qiagen). Lysate preparation was described elsewhere (Seo et al. 2005). Anti-Brg1 antibody (Upstate), raised against hBrg1 amino acids 214-279, was cross-linked to Protein-A beads with ImmunoPure Protein A IgG Orientation Kit (Pierce) and used for co-IP. IP was performed for $6 \mathrm{~h}$ or overnight at $4^{\circ} \mathrm{C}$, and beads were collected and washed four times with lysis buffer. For interaction domain mapping, HEK293 cells were transfected with $2 \mu \mathrm{g}$ of each indicated construct in $60-\mathrm{mm}$ dishes and harvested $30-48 \mathrm{~h}$ after transfection. For competition assays, cells were transfected with $2 \mu \mathrm{g}$ of CS2MT-Brg1, $1 \mu \mathrm{g}$ of CS2FL-Ngnr1 or CS2FL-NeuroD, and $4 \mu$ of CS2HA-Gem, CS2HA-Gem $\Delta(\mathrm{BD})$, or CS2HA in 60-mm dishes and used for co-IP as above. Antibodies used were Gem (FL-209 and N-18; Santa Cruz), E-cadherin (BD Biosciences), p2 $7^{\text {Kip1 }}$ (BD Biosciences), and actin (H-300; Santa Cruz).

\section{Fly strains and scanning electron microscope analysis}

Drosophila strains were described previously (Elfring et al. 1998; Quinn et al. 2001; Brumby et al. 2002). Overexpression of $\mathrm{Brm}^{\text {K804R }}$ in the eye was driven by the glass multimer reporter (GMR)-Gal4 driver. Flies were prepared for scanning electron microscopy by dehydration in acetone, followed by air-drying. Eyes were viewed without coating using a field emission scanning electron microscope. Sectioning and staining was carried out as previously described (Lockett et al. 1993). The C96-GAL4 driver was used to overexpress UAS-Brm ${ }^{\text {K804R }}$ and UAS-Gem in the wing pouch of third instar larvae.

Embryos, RNA/morpholino oligonucleotides injection, and whole-mount in situ hybridization

Acquisition of embryos, RNA/MO injection, and whole-mount in situ hybridization were described previously (Kroll et al. 1998; Seo et al. 2005). RNAs for Ngnr1 (25 pg), NeuroD (50 pg), $\operatorname{Gem} \Delta(\operatorname{coil}), \operatorname{Gem} \Delta(\operatorname{coill}) 5 \mathrm{EQ}, \operatorname{Gem} \Delta(\operatorname{coil}) \Delta(\mathrm{BD})(800 \mathrm{pg})$, or
GemCT, GemCT(3EA) (1 ng) were injected with $30 \mathrm{pg}$ of LacZ RNA as a lineage tracer in a volume of $8 \mathrm{~nL}$ into a single blastomere of two-cell stage embryos. Specificity and effectiveness of $\operatorname{Brg} 1 \mathrm{MO}$ (5'-TCACTGCTAACCTGTCCCCGAATCC-3'), GemMO (5'-ATCTCTGCTTCTTGTTGGTATTCAT-3'), and the standard control MO (5'-CCTCTTACCTCAGTTACAAT TTATA-3') (GeneTools LLC) were described previously (McGarry 2002; Seo et al. 2005).

P19 cell culture, transfection, immunofluorescence, luciferase assay, and $R A$ induction

Maintenance of P19 cells, transfection, TuJ1-immunostaining, and luciferase assay were performed as previously described (Farah et al. 2000; Seo et al. 2005). RA induction was performed as described (Jones-Villeneuve et al. 1982), and an aliquot of cells was harvested every $24 \mathrm{~h}$. Protein concentrations were determined using Protein Assay (Bio-Rad), and lysates were applied for Western blotting to analyze gene expression profiles. For Gem loss-of-function study, P19 cells were transfected with $2.4 \mu \mathrm{g}$ of indicated U6 vectors and harvested at $44 \mathrm{~h}$ post-transfection for Western or with $50 \mathrm{ng}$ of NeuroD2, $500 \mathrm{ng}$ of eGFP, and $2.4 \mu \mathrm{g}$ of indicated U6 vector and processed as above for TuJ1-immunostaining.

\section{Acknowledgments}

We thank D. Turner for U6 plasmids and mouse bHLH expression vectors, and William Harris, Raphael Kopan, Nancy Papalopulu, and Min-Ho Lee for critical reading of the manuscript. This work was supported by grants from the NIH (GM66815-1), the Pfizer/Washington University Biomedical Research Program, the Whitehall Foundation, and the March of Dimes to K.K.

\section{References}

Bain, G., Kitchens, D., Yao, M., Huettner, J.E., and Gottlieb, D.I. 1995. Embryonic stem cells express neuronal properties in vitro. Dev. Biol. 168: 342-357.

Ballabeni, A., Melixetian, M., Zamponi, R., Masiero, L., Marinoni, F., and Helin, K. 2004. Human Geminin promotes pre$\mathrm{RC}$ formation and DNA replication by stabilizing CDT1 in mitosis. EMBO I. 23: 3122-3132.

Berkes, C.A., Bergstrom, D.A., Penn, B.H., Seaver, K.J., Knoepfler, P.S., and Tapscott, S.J. 2004. Pbx marks genes for activation by MyoD indicating a role for a homeodomain protein in establishing myogenic potential. Mol. Cell 14: 465-477.

Bertrand, N., Castro, D.S., and Guillemot, F. 2002. Proneural genes and the specification of neural cell types. Nat. Rev. Neurosci. 3: 517-530.

Brumby, A.M., Zraly, C.B., Horsfield, J.A., Secombe, J., Saint, R., Dingwall, A.K., and Richardson, H. 2002. Drosophila cyclin $\mathrm{E}$ interacts with components of the Brahma complex. EMBO J. 21: 3377-3389.

Bylund, M., Andersson, E., Novitch, B.G., and Muhr, J. 2003. Vertebrate neurogenesis is counteracted by Sox $1-3$ activity. Nat. Neurosci. 6: 1162-1168.

Chae, J.H., Stein, G.H., and Lee, J.E. 2004. NeuroD: The predicted and the surprising. Mol. Cell 18: 271-288.

Chalmers, A.D., Welchman, D., and Papalopulu, N. 2002. Intrinsic differences between the superficial and deep layers of the Xenopus ectoderm control primary neuronal differentiation. Dev. Cell 2: 171-182.

Cremisi, F., Philpott, A., and Ohnuma, S. 2003. Cell cycle and 
cell fate interactions in neural development. Curr. Opin. Neurobiol. 13: 26-33.

de la Serna, I.L., Carlson, K.A., and Imbalzano, A.N. 2001a. Mammalian SWI/SNF complexes promote MyoD-mediated muscle differentiation. Nat. Genet. 27: 187-190.

de la Serna, I.L., Roy, K., Carlson, K.A., and Imbalzano, A.N. 2001b. MyoD can induce cell cycle arrest but not muscle differentiation in the presence of dominant negative SWI/ SNF chromatin remodeling enzymes. J. Biol. Chem. 276: 41486-41491.

de la Serna, I.L., Ohkawa, Y., Berkes, C.A., Bergstrom, D.A., Dacwag, C.S., Tapscott, S.J., and Imbalzano, A.N. 2005. MyoD targets chromatin remodeling complexes to the myogenin locus prior to forming a stable DNA-bound complex. Mol. Cell. Biol. 25: 3997-4009.

Del Bene, F., Tessmar-Raible, K., and Wittbrodt, J. 2004. Direct interaction of geminin and Six3 in eye development. Nature 427: 745-749.

Elfring, L.K., Daniel, C., Papoulas, O., Deuring, R., Sarte, M., Moseley, S., Beek, S.J., Waldrip, W.R., Daubresse, G., DePace, A., et al. 1998. Genetic analysis of brahma: The Drosophila homolog of the yeast chromatin remodeling factor SWI2/SNF2. Genetics 148: 251-265.

Farah, M.H., Olson, J.M., Sucic, H.B., Hume, R.I., Tapscott, S.J., and Turner, D.L. 2000. Generation of neurons by transient expression of neural bHLH proteins in mammalian cells. Development 127: 693-702.

Francis, N.J., Saurin, A.J., Shao, Z., and Kingston, R.E. 2001. Reconstitution of a functional core polycomb repressive complex. Mol. Cell 8: 545-556.

Gao, X., Bian, W., Yang, J., Tang, K., Kitani, H., Atsumi, T., and Jing, N. 2001. A role of N-cadherin in neuronal differentiation of embryonic carcinoma P19 cells. Biochem. Biophys. Res. Commun. 284: 1098-1103.

Gebuhr, T.C., Bultman, S.J., and Magnuson, T. 2000. Pc-G/ trx-G and the SWI/SNF connection: Developmental gene regulation through chromatin remodeling. Genesis 26: 189197.

Gonzalez, M.A., Tachibana, K.E., Chin, S.F., Callagy, G., Madine, M.A., Vowler, S.L., Pinder, S.E., Laskey, R.A., and Coleman, N. 2004. Geminin predicts adverse clinical outcome in breast cancer by reflecting cell-cycle progression. $J$. Pathol. 204: 121.

Graham, V., Khudyakov, J., Ellis, P., and Pevny, L. 2003. SOX2 functions to maintain neural progenitor identity. Neuron 39: 749-765.

Jones-Villeneuve, E.M., McBurney, M.W., Rogers, K.A., and Kalnins, V.I. 1982. Retinoic acid induces embryonal carcinoma cells to differentiate into neurons and glial cells. $J$. Cell. Biol. 94: 253-262.

Kadam, S. and Emerson, B.M. 2003. Transcriptional specificity of human SWI/SNF BRG1 and BRM chromatin remodeling complexes. Mol. Cell 11: 377-389.

Kingston, R.E. and Narlikar, G.J. 1999. ATP-dependent remodeling and acetylation as regulators of chromatin fluidity. Genes \& Dev. 13: 2339-2352.

Kroll, K.L., Salic, A.N., Evans, L.M., and Kirschner, M.W. 1998. Geminin, a neuralizing molecule that demarcates the future neural plate at the onset of gastrulation. Development 125: 3247-3258.

Lee, J.E., Hollenberg, S.M., Snider, L., Turner, D.L., Lipnick, N., and Weintraub, H. 1995. Conversion of Xenopus ectoderm into neurons by NeuroD, a basic helix-loop-helix protein. Science 268: 836-844.

Lockett, T.J., Moretti, P.A., Lake, J.A., and Saint, R. 1993. Rough genes with Deformed homeobox substitutions exhibit rough regulatory specificity during Drosophila eye development. Mech. Dev. 41: 57-68.

Luo, L. and Kessel, M. 2004. Geminin coordinates cell cycle and developmental control. Cell Cycle 3: 711-714.

Luo, L., Yang, X., Takihara, Y., Knoetgen, H., and Kessel, M. 2004. The cell-cycle regulator geminin inhibits Hox function through direct and polycomb-mediated interactions. Nature 427: 749-753.

Ma, Q., Kintner, C., and Anderson, D.J. 1996. Identification of neurogenin, a vertebrate neuronal determination gene. Cell 87: 43-52.

Markey, M.P., Siddiqui, H., and Knudsen, E.S. 2004. Geminin is targeted for repression by the retinoblastoma tumor suppressor pathway through intragenic E2F sites. J. Biol. Chem.. 279: 29255-29262.

Martens, J.A. and Winston, F. 2003. Recent advances in understanding chromatin remodeling by Swi/Snf complexes. Curr. Opin. Genet. Dev. 13: 136-142.

McBurney, M.W. 1993. P19 embryonal carcinoma cells. Int. J. Dev. Biol. 37: 135-140.

McGarry, T.J. 2002. Geminin deficiency causes a Chk1-dependent G2 arrest in Xenopus. Mol. Biol. Cell 13: 3662-3671.

McGarry, T.J. and Kirschner, M.W. 1998. Geminin, an inhibitor of DNA replication, is degraded during mitosis. Cell 93: 1043-1053.

Melixetian, M., Ballabeni, A., Masiero, L., Gasparini, P., Zamponi, R., Bartek, J., Lukas, J., and Helin, K. 2004. Loss of Geminin induces rereplication in the presence of functional p53. J. Cell. Biol. 165: 473-482.

Mihaylov, I.S., Kondo, T., Jones, L., Ryzhikov, S., Tanaka, J., Zheng, J., Higa, L.A., Minamino, N., Cooley, L., and Zhang, H. 2002. Control of DNA replication and chromosome ploidy by geminin and cyclin A. Mol. Cell. Biol. 22: 18681880.

Mizuseki, K., Kishi, M., Matsui, M., Nakanishi, S., and Sasai, Y. 1998. Xenopus Zic-related-1 and Sox-2, two factors induced by chordin, have distinct activities in the initiation of neural induction. Development 125: 579-587.

Molofsky, A.V., Pardal, R., Iwashita, T., Park, I.K., Clarke, M.F., and Morrison, S.J. 2003. Bmi-1 dependence distinguishes neural stem cell self-renewal from progenitor proliferation. Nature 425: 962-967.

Montanari, M., Boninsegna, A., Faraglia, B., Coco, C., Giordano, A., Cittadini, A., and Sgambato, A. 2005. Increased expression of geminin stimulates the growth of mammary epithelial cells and is a frequent event in human tumors. J. Cell. Physiol. 202: 215-222.

Ohnuma, S. and Harris, W.A. 2003. Neurogenesis and the cell cycle. Neuron 40: 199-208.

Park, I.K., Qian, D., Kiel, M., Becker, M.W., Pihalja, M., Weissman, I.L., Morrison, S.J., and Clarke, M.F. 2003. Bmi-1 is required for maintenance of adult self-renewing haematopoietic stem cells. Nature 423: 302-305.

Penzel, R., Oschwald, R., Chen, Y., Tacke, L., and Grunz, H. 1997. Characterization and early embryonic expression of a neural specific transcription factor XSOX3 in Xenopus laevis. Int. J. Dev. Biol. 41: 667-677.

Peterson, C.L. and Logie, C. 2000. Recruitment of chromatin remodeling machines. J. Cell. Biochem. 78: 179-185.

Quinn, L.M., Herr, A., McGarry, T.J., and Richardson, H. 2001. The Drosophila Geminin homolog: Roles for Geminin in limiting DNA replication, in anaphase and in neurogenesis. Genes \& Dev. 15: 2741-2754.

Roy, K., de la Serna, I.L., and Imbalzano, A.N. 2002. The myogenic basic helix-loop-helix family of transcription factors shows similar requirements for SWI/SNF chromatin remod- 
Seo et al.

eling enzymes during muscle differentiation in culture. $J$. Biol. Chem. 277: 33818-33824.

Saxena, S., Yuan, P., Dhar, S.K., Senga, T., Takeda, D., Robinson, H., Kornbluth, S., Swaminathan, K., and Dutta, A. 2004. A dimerized coiled-coil domain and an adjoining part of geminin interact with two sites on cdt1 for replication inhibition. Mol. Cell 15: 245-258.

Seo, S., Richardson, G.A., and Kroll, K.L. 2005. The SWI/SNF chromatin remodeling protein $\mathrm{Brg} 1$ is required for vertebrate neurogenesis and mediates transactivation of Ngn and NeuroD. Development 132: 105-115.

Simone, C., Forcales, S.V., Hill, D.A., Imbalzano, A.N., Latella, L., and Puri, P.L. 2004. p38 pathway targets SWI-SNF chromatin-remodeling complex to muscle-specific loci. Nat. Genet. 36: 738-743.

Tada, S., Li, A., Maiorano, D., Mechali, M., and Blow, J.J. 2001. Repression of origin assembly in metaphase depends on inhibition of RLF-B/Cdt1 by geminin. Nat. Cell. Biol. 3: 107113.

Vernon, A.E., Devine, C., and Philpott, A. 2003. The cdk inhibitor $\mathrm{p} 27 \mathrm{Xic} 1$ is required for differentiation of primary neurones in Xenopus. Development 130: 85-92.

Vojtek, A.B., Taylor, J., DeRuiter, S.L., Yu, J.Y., Figueroa, C., Kwok, R.P., and Turner, D.L. 2003. Akt regulates basic helix-loop-helix transcription factor-coactivator complex formation and activity during neuronal differentiation. Mol. Cell. Biol. 23: 4417-4427.

Whitehouse, I., Flaus, A., Cairns, B.R., White, M.F., Workman, J.L., and Owen-Hughes, T. 1999. Nucleosome mobilization catalysed by the yeast SWI/SNF complex. Nature 400: 784787.

Wohlschlegel, J.A., Dwyer, B.T., Dhar, S.K., Cvetic, C., Walter, J.C., and Dutta, A. 2000. Inhibition of eukaryotic DNA replication by geminin binding to Cdt1. Science 290: 23092312.

Wohlschlegel, J.A., Kutok, J.L., Weng, A.P., and Dutta, A. 2002. Expression of geminin as a marker of cell proliferation in normal tissues and malignancies. Am. J. Pathol. 161: 267273.

Yoshida, K. and Inoue, I. 2004. Regulation of Geminin and Cdt1 expression by E2F transcription factors. Oncogene 23: 38023812.

Zhu, W., Chen, Y., and Dutta, A. 2004. Rereplication by depletion of Geminin is seen regardless of p53 status and activates a G2/M checkpoint. Mol. Cell. Biol. 24: 71407150 . 


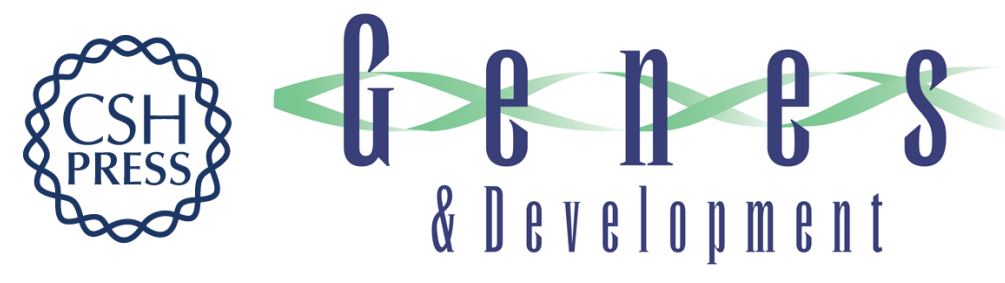

\section{Geminin regulates neuronal differentiation by antagonizing Brg1 activity}

Seongjin Seo, Anabel Herr, Jong-Won Lim, et al.

Genes Dev. 2005, 19:

Access the most recent version at doi:10.1101/gad.1319105

Supplemental
Material http://genesdev.cshlp.org/content/suppl/2005/07/12/19.14.1723.DC1

References This article cites 56 articles, 21 of which can be accessed free at: http://genesdev.cshlp.org/content/19/14/1723.full.html\#ref-list-1

\section{License}

Email Alerting

Receive free email alerts when new articles cite this article - sign up in the box at the top

Service

right corner of the article or click here.

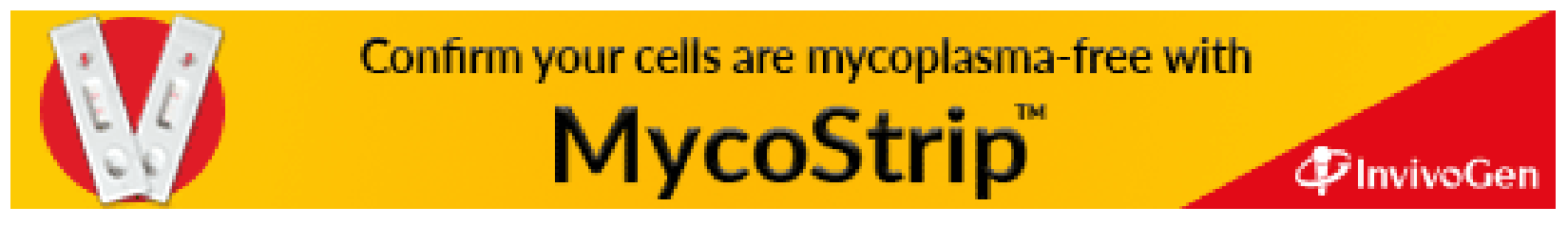

